Research Article

\title{
Measurement and Simulation Analysis of Vertical Cross Longitudinal Settlement between Turning Shield and Foundation Pit
}

\author{
Hua Yin ${ }^{D}$, Hong Zhang $\mathbb{D}$, and Rui Zhang \\ Transportation Institute, Inner Mongolia University, Hohhot 010070, China \\ Correspondence should be addressed to Hong Zhang; zhanghong3537@126.com
}

Received 17 December 2020; Revised 19 March 2021; Accepted 7 May 2021; Published 24 May 2021

Academic Editor: Arnaud Perrot

Copyright ( $\odot 2021$ Hua Yin et al. This is an open access article distributed under the Creative Commons Attribution License, which permits unrestricted use, distribution, and reproduction in any medium, provided the original work is properly cited.

\begin{abstract}
Using numerical simulation technology, the dynamic three-dimensional model of the turning shield and the foundation pit under the condition of vertical intersection is established. The disturbance law of the longitudinal settlement of the foundation pit under the condition of shield construction is studied, and the stress path in the soil is analyzed. The results show that with the gradual advance of the turning shield construction, the settlement mode of the foundation pit changes with the shield construction. During the construction of the turning shield, when the tunnel face is located in front of the foundation pit and under the foundation pit, the ground loss rate is inconsistent, which leads to the change of settlement mode. Under the influence of turning shield construction disturbance, the soil undergoes compression deformation caused by larger additional stress increase; after shield crossing, the soil undergoes unloading deformation caused by more obvious stress relaxation.
\end{abstract}

\section{Introduction}

The shield method is the most commonly used construction method for urban subway tunnel construction. With the increasingly tense urban space, it is inevitable for an urban shield tunnel to cross under and side through the existing building structure. The disturbance impact on the surrounding building structure is a problem that must be considered in the shield construction of urban subway tunnel; aiming at the settlement disturbance analysis of surrounding buildings caused by shield construction of urban subway tunnel, scholars have analyzed such problems from the perspectives of construction monitoring [1-3], theoretical analysis [4-8], and numerical simulation $[9-13,31]$. There are many related research results, most of which are lateral disturbance analysis of straight-line section shield, while there is less analysis on the disturbance of existing building structure caused by the construction of turning shield tunnel, the interaction mechanism between turning shield tunnel excavation and existing buildings is more complex, which is affected by turning radius, advance excavation volume, ground conditions, tunnel structural characteristics, relative space position between shield and tunnel, type of shield machine, shield construction parameters, and whole process [14-18]. In the related research of the shield method, most experts and scholars have made a detailed analysis from the perspectives of theoretical analysis, numerical simulation, and field monitoring. The existing theoretical studies include the calculation theory of ground loss and the deformation prediction model of ground and surrounding buildings caused by construction. In the analysis of the construction of a turning shield tunnel, the theoretical analysis method is difficult to accurately consider the deformation disturbance caused by various loads on the construction site, and the calculation results will inevitably deviate from the actual, while the field monitoring method is difficult to investigate the disturbance deformation mechanism. Different from the straight-line shield tunnel, the turning shield tunnel can be regarded as a series of discontinuous straight lines [19], but the theoretical calculation and field monitoring are difficult to achieve this process. As the most accurate and 
effective method in disturbance analysis of the turning shield, the numerical simulation method can be used to simulate the influence of different working conditions on ground loss and ground structure [20]. Therefore, the numerical simulation model under the condition of vertical intersection between turning shield tunnel and existing foundation pit is established, the accuracy of the numerical simulation model is verified by theoretical calculation and field monitoring data, and the disturbance effect of shield construction on the existing foundation pit is analyzed by the numerical simulation model.

Aiming at the disturbance of shield construction to surrounding buildings, experts and scholars have carried out multiangle analysis. Most of them focus on the analysis of building disturbance along the transverse direction of the excavation tunnel in the process of shield tunneling directly. Vgerinos et al. [21] established a numerical simulation model, under the cross conditions of shield construction and existing tunnels, conducted an analysis of the disturbance of the shield construction to the tunnel. Li et al. [22], based on the theoretical derivation method of Timoshenko beam solution, analyzed the disturbance of shield construction to the existing tunnel. Based on Shanghai metro tunnel, $\mathrm{Wu}$ et al. [23] proposed a new longitudinal structure model considering shear dislocation between rings, which can reasonably describe the actual deformation mode of the tunnel. Lin et al. [24] analyzed the variation of ground settlement trough and Earth pressure acting on the existing tunnel during the construction of shield tunnel. On this basis, the transverse deformation, internal force, and torsion characteristics of the existing tunnel caused by the new tunnel excavation are obtained. In addition, the influence of the intersection angle of new and old tunnels on the deformation behavior of existing tunnels is also discussed. Under the working condition of soft soil foundation, Do et al. [25] established a three-dimensional numerical simulation model and studied its disturbance effect. So far, aiming at the problem of disturbance analysis of horizontal buildings caused by linear shield excavation, there has been a lot of research, but there is little research on the construction tunnel along the longitudinal direction of the excavation tunnel and the disturbance analysis of the curve tunnel with a small turning radius. Based on the project of Hohhot Metro Line 1 in Inner Mongolia, based on the combination of numerical simulation and construction site monitoring, this paper analyzes the disturbance of small turning radius shield tunnel excavation to longitudinal buildings. The numerical simulation model of shield excavation with a small curvature radius is based on mirror-image method and Mindlin solution [26, 27]; combined with the field monitoring data, this paper deduces the calculation formula of the tunnel longitudinal building structure settlement caused by the construction of the small curvature radius curve shield tunnel and calculates and analyzes the longitudinal ground loss along with the tunnel excavation and the longitudinal settlement law of the surface foundation pit, which provides a theoretical basis for the construction disturbance analysis under the cross condition of the turning shield tunnel and the existing foundation pit.

\section{Project Overview}

The total length of Hohhot Metro Line 1 is $21.7 \mathrm{~km}$, in which the left line of a small curvature turning section is $327.6 \mathrm{~m}$, the right line is $326.1 \mathrm{~m}$ long, the outer diameter of the shield tunnel is $6.5 \mathrm{~m}$, the segment thickness is $0.35 \mathrm{~m}$, and the average distance between left and right tunnel center lines in shield interval is $14 \mathrm{~m}$. The buried depth of the subway tunnel is $20.8 \mathrm{~m}$, while the buried depth of the tunnel bottom is $10.5 \mathrm{~m}$. The clear distance between the tunnel bottom and the outer edge of the shield top of the right tunnel of Metro Line 2 is $10.5 \mathrm{~m}$. Open cut method is adopted for this section of tunnel. The cross section is mainly composed of gravel sand and silty clay, and the depth of foundation pit is $10.8 \mathrm{~m}$. The buried depth of the shield tunnel in this section is $9 \sim 14 \mathrm{~m}$, and the section includes a small radius turning shield tunnels, with a turning radius of $810 \mathrm{~m}$; settlement measuring points are arranged on the ground, and 40 measuring points are set on the longitudinal ground of the shield tunnel. According to the technical requirements of leveling, the ground and building settlement data are monitored in real time during the construction of the shield tunnel. The plane diagram of the foundation pit, measuring point, and shield tunnel is shown in Figure 1.

\section{Theoretical Calculation Model}

3.1. Ground Loss in Excavation Face and Shield. In the calculation model of turning shield tunnel, it is necessary to consider the large volume of overbreak on the soil inside the curve, the uneven distribution of thrust on the excavation face due to the large stroke of jack on the outside of the route, and the different thrust distribution of the excavation face caused by the extrusion of the soil mass by the shield shell inside the line, which leads to the uneven ground loss along the excavation transverse direction, which is different from the straight-line shield tunnel. The theoretical calculation model of excavation, involving the curve shield excavation model, is more complex, the existing calculation model is mostly linear shield excavation ground loss calculation model, less established curve excavation ground loss theoretical calculation model. In this part, the stratum loss model of curved shield tunnel construction is divided into two parts. The first part is the stratum loss within the scope of the excavation face and shield shell. The stratum loss profile of this part is generated by the whole process from the extension of overbreak cutter-to-the cutter contraction, and the void range starts from the excavation face and extends to the shield tail. The coordinate transformation is as follows [28]:

$$
\left\{\begin{array}{l}
x_{0}=r \cos \theta \\
y_{0}=y-s \\
z_{0}=H-r \sin \theta
\end{array}\right.
$$

The formula is substituted into the image method to calculate the formation loss: 


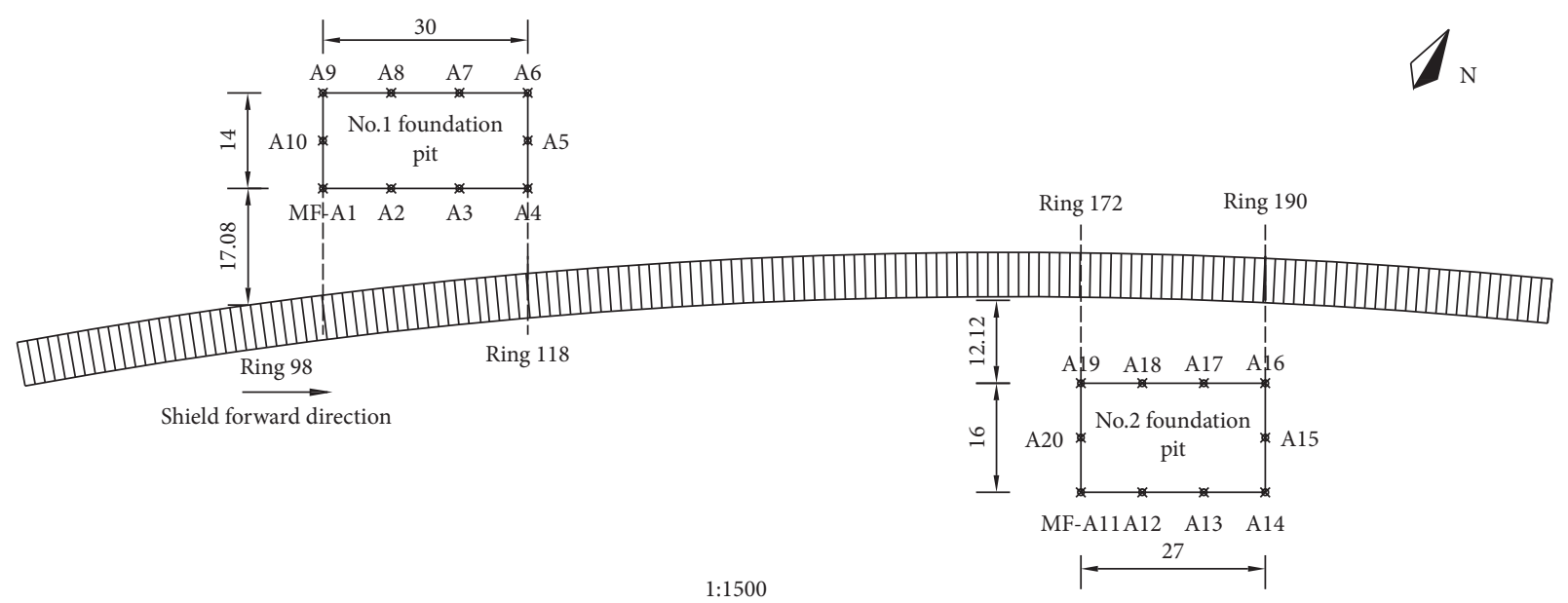

Figure 1: Plane diagram.

$$
\begin{aligned}
w_{z 1} & =\iiint_{v_{1}} S_{2} \mathrm{~d} \theta \mathrm{d} r \mathrm{~d} s-\iiint_{v_{2}} S_{2} \\
& =\int_{-\pi / 2+\beta}^{\pi / 2-\beta} \int_{R}^{R+\delta} \int_{0}^{L}\left(S_{0}+S_{s 1}+S_{s 2}\right) \mathrm{d} \theta \mathrm{d} r \mathrm{~d} s,
\end{aligned}
$$

where

$$
\begin{aligned}
V_{1} & =S_{1} \cdot s, \\
V_{2} & =S_{2} \cdot s, \\
r_{1} & =\left[(x-r \cos \theta)^{2}+(y-s)^{2}+(z+H+r \sin \theta)^{2}\right]^{1 / 2}, \\
r_{2} & =\left[(x-r \cos \theta)^{2}+(y-s)^{2}+(z+H-r \sin \theta)^{2}\right]^{1 / 2} .
\end{aligned}
$$

$s$ is the distance between the calculation point and the cutter head; $S_{1}$ is the area of excavated soil and overexcavated soil; $S_{2}$ is the area of cutter head; $V_{1}$ is the volume of excavated soil and overexcavated soil; and $V_{2}$ is the cutter head volume.

3.2. Formation Loss at Shield Tail. The second part is the formation loss at the tail of the shield, which is the superposition of overbreak profile and stratum loss profile of the shield tail. The deformation of this part of soil adopts the equal radial movement mode. The model assumes that the soil is undrained, and its volume is incompressible, and the volume of the ground settlement tank is equal to the volume of soil loss. According to the research results of Sagaseta, the land subsidence formula of this part is as follows [28]:

$$
w_{3}=\frac{V_{\text {loss }}}{2 \pi} \frac{h}{y^{2}+h^{2}}\left(1-\frac{x}{\sqrt{x^{2}+y^{2}+h^{2}}}\right)
$$

where $V_{\text {loss }}=$ soil loss per unit length of tunnel $\left(\mathrm{m}^{3} / \mathrm{m}\right)$.

(1) Calculation of Ground Deformation Caused by Front Additional Stress

Taking the differential area in the excavation face under the action of the front additional thrust, the vertical deformation of the ground caused by the front additional thrust is obtained by integrating the Mindlin solution in elastic mechanics, and the calculation formula is as follows:

$$
w_{1}=\frac{P x}{4 \pi G} \int_{0}^{2 \pi} \int_{0}^{D / 2}\left[\frac{-h+r \sin \theta}{W_{1}^{3}}+\frac{1-2 \nu}{W_{1}\left(W_{1}+h-r \sin \theta\right)}\right] r \mathrm{~d} r \mathrm{~d} \theta
$$

where $X=$ horizontal distance between heading direction and excavation face $(\mathrm{m}) ; P=$ additional thrust of shield face $(\mathrm{kPa}) ; D=$ shield diameter $(\mathrm{m})$; $H=$ buried depth of tunnel axis (m); and $G=$ shear modulus of elasticity of soil (MPa).
(2) Calculation of Ground Deformation Caused by Friction between Shield and Soil

Taking the differential area of shield machine surface, using Mindlin solution, the calculation formula of ground vertical deformation caused by friction 
between shield shell and soil is obtained by direct integration of shield machine surface [29]:

$$
w_{2}=\frac{p R}{4 \pi G} \int_{0}^{2 \pi} \int_{0}^{L}(x+l)+\left[\left[\frac{-h+R \sin \theta}{W_{2}^{3}}+\frac{1-2 \mu}{W_{2}\left(W_{2}+h-R \sin \theta\right)}\right] \mathrm{d} l \mathrm{~d} \theta\right.
$$

\begin{abstract}
where $L=$ shield machine length $(m)$; $W_{2}=\sqrt{(x+l)^{2}+(y+R \cos \theta)^{2}+(h-R \sin \theta)^{2}}$;

$R=$ outer diameter of shield machine $0(\mathrm{~m})$; and $p=$ friction force per unit area between shield and soil $(\mathrm{kPa})$.
\end{abstract}

\section{Numerical Simulation Model}

4.1. Shield Excavation Model. To further analyze the influence of small-radius turning shield construction on the spatial deformation mechanism of longitudinal buildings, ABAQUS is used to establish the finite element numerical simulation model. In this paper, the Mohr-Coulomb plastic model is adopted as the soil constitutive model. The model is suitable for various soil properties such as clay and sand, which is more consistent with the typical soil characteristics of Hohhot city. The soil layer and its soil mechanical indexes along the metro line are shown in Table 1; the soil layer type of shield crossing in this section is mainly silty clay. According to the research results of Mollon et al. [2, 30] combined with the actual working conditions, the minimum tunnel length to eliminate the boundary conditions of the model is $110 \mathrm{~m}$, so the $3 \mathrm{D}$ model established by numerical simulation software is $120 \mathrm{~m}$, and the boundary condition constraint mode is displacement/rotation mode. The normal displacement (perpendicular to the boundary direction) is constrained on the four sides of the numerical analysis model. The upper surface of the model is not constrained and is allowed to move freely, and the bottom boundary is completely fixed. According to the actual working conditions, a three-dimensional dynamic numerical simulation model of shield excavation is established. The dynamic tunnel excavation process is that the unit killing method is used to excavate the shield, and then the lining construction and shield tail grouting construction are carried out, the unit killing process is to change the Young modulus of the soil in front of the shield to simulate the excavation process. At the same time, the Young modulus of the soil in the first ring of the shield tail is dynamically changed, and the grouting pressure is applied to simulate the grouting and hardening process of the shield tail. The longitudinal settlement caused by shield construction can be divided into five stages: first settlement, settlement before excavation, settlement through shield body, clearance settlement at shield tail, and consolidation settlement. Settlement and settlement before excavation refer to the settlement of surrounding soil and foundation pit before the tunnel face reaches the monitoring point, the settlement of shield body refers to the settlement caused by the movement of shield machine during tunnel construction, the settlement caused by the clearance of shield tail after the soil is cleared, and the settlement caused by consolidation refers to the soil settlement caused by the redistribution of stress in the soil after the completion of excavation and the soil entering the consolidation stage.

4.1.1. Face Pressure. During the establishment of the shield excavation model, the method of importing ODB from ABAQUS is used for in situ stress balance. Then, the numerical model of vertical cross between foundation pit and shield is established.

During shield construction, the surface pressure changes linearly with height and soil density. According to the research results of Do et al. [30], the surface pressure at the axis of the shield tunnel is generally equal to $50 \%$ of the total horizontal ground stress, that is, the sum of the stress on the top of the tunnel and the stress on the opposite side of the tunnel. In the excavation model, the tunnel surface pressure at the tunnel axis is set to $200 \mathrm{kPa}$.

4.1.2. Grouting Pressure of Shield Tail. The grouting pressure at the tail of the shield is the grouting pressure in the gap between the tunnel lining and the outer wall after the shield excavation. According to the actual working conditions, the grouting pressure is equivalent to the uniform load and is positively correlated with the top ground pressure. The grouting pressure of the shield tail is calculated according to the following formula:

$$
\sigma_{\mathrm{p}}=1.2 \cdot \sigma_{v}
$$

where $\sigma_{v}=\gamma(h-R) ; \gamma$ is the soil density; and $h$ is the tunnel depth.

4.1.3. Turning Shield Model. In the straight-line shield tunnel, the jacking pressure of the hydraulic jack on the face is equivalent to a uniform load, which acts on the face plane, and its size is $3.421 \mathrm{MPa}$. In the turning section of the tunnel, the jacking force acting on the tunnel face pushes the shield machine forward. The surface subjected to the jacking force is divided into the inside and outside of the curved channel. According to the field monitoring data, the average ratio of the jacking force between the outer and inner sides is close to 2. Based on this ratio, the total force of hydraulic jacking is adjusted on the corresponding area of each segment in the model. Therefore, the uniformly distributed pushing pressure acting on the inner and outer sides of the circle of the section is $2.312 \mathrm{MPa}$ and $4.571 \mathrm{MPa}$, respectively. In addition, the direction of the jacking force is inclined to the 
TABLE 1: Material parameter.

\begin{tabular}{|c|c|c|c|c|c|c|c|c|c|}
\hline Sequence & Layer & Thickness (m) & $c(\mathrm{kPa})$ & $\varphi\left({ }^{\circ}\right)$ & $\rho\left(\mathrm{kg} \cdot \mathrm{m}^{-3}\right)$ & $k\left(\mathrm{~m} \cdot \mathrm{d}^{-1}\right)$ & $E_{50}^{\text {ref }}(\mathrm{MPa})$ & $E_{\text {oed }}^{\text {ref }}(\mathrm{MPa})$ & $E_{\mathrm{ur}}^{\mathrm{ref}}(\mathrm{MPa})$ \\
\hline (1) 3 & Artificial fill & 2.8 & 2.4 & 11.7 & 1500 & 1 & 3 & 3 & 9 \\
\hline (2) & Silt & 3.2 & 1.0 & 20.4 & 2040 & 0.3 & 12.5 & 10 & 37.5 \\
\hline (2) 1 & Silt & 4.1 & 1.1 & 18.9 & 2100 & 0.3 & 11.3 & 9.8 & 28.7 \\
\hline (4) 1 & Silty clay & 13.2 & 21.4 & 15.7 & 1950 & 0.5 & 10 & 6 & 30 \\
\hline (6) 5 & Silt & 8.6 & 2.6 & 29.7 & 1920 & 3 & 12.7 & 10.4 & 36.4 \\
\hline (6) 6 & Silt & 7.8 & 3.7 & 26.9 & 2050 & 3 & 13.2 & 13.2 & 41.2 \\
\hline (7) 2 & Fine sand & 6.4 & 5.7 & 18.4 & 1900 & 5 & 13.5 & 13.5 & 40 \\
\hline (10) 1 & Gravelly sand & 10.8 & 4.1 & 27.6 & 2030 & 50 & 13.4 & 13.5 & 39.4 \\
\hline (10) 2 & Gravelly sand & 28.4 & 5.3 & 26.9 & 2000 & 60 & 13.7 & 13.7 & 40.5 \\
\hline
\end{tabular}

outside of the curved tunnel by an angle $\alpha$, which is equal to that of the shield advancing forward by one ring, and the distance is the angle of the segment ring. In practical engineering, it is difficult to measure and quantify the friction between shield machine shell and surrounding soil. Assuming mechanical balance, the difference between the jacking force acting on the pipe section and the thrust acting on the working face of the foundation pit is used to approximate the friction force. Similarly, the outer ring surface of the shield machine is also divided into internal and external regions, and the friction force per unit area is $54 \mathrm{kPa}$ and $102 \mathrm{kPa}$, respectively. The friction sliding model is established by a contact pair composed of shield skin and excavation interface. In ABAQUS, Coulomb's friction law is adopted, and the friction coefficient is 0.25 [7].

In the finite element model design of shield excavation, the excavation process along the tunnel axis is divided into different stages, and the corresponding finite element model program is designed for each excavation stage. In the first stage of excavation, the original soil layer is removed and the material properties of the original soil layer are changed. At the same time, the shield jacking pressure acts on the surface of the next layer, and the friction contact in the current layer is activated. At the end of the shield machine, the grouting pressure is applied, and the elastic model of the cement slurry is gradually improved to simulate the hardening process of the slurry. With the gradual advance of the shield machine, the elastic modulus of the cement slurry is finally increased to $500 \mathrm{MPa}$.

The process of shield excavation consists of a series of stages, each of which follows a series of procedures, which leads to the increase of the width of a ring. Taking stage " $n$ " as an example, the simulation of excavation of curved shield tunnel is as follows: in the current excavation stage, when the " $n$ " of ground section is removed, the material characteristics of the overcutting elements will change. At the same time, the pressure from shield jacking will be applied to the surface of section " $n+1$." With the development of shield tail from "N-7" layer to " $n-1$," when the shield layer "N-7" is removed, the shielding and friction contact pairs at layer " $n$ " are activated. At the same time, the specified friction force is applied to the outer ring of the shield " $n$." Segment installation is performed by activating segment "N-7" and the specified jacking force is applied to segment "N-7." The "synchronous grouting" at the tail of shield (section "N-7") is realized by applying the specified grouting pressure on the ground and section after the grouting pressure acting on the section "N-8" is removed. In addition, the grouting element (modulus of elasticity is $30 \mathrm{MPa}$ ) is activated in this step. With the development of shield machine, the elastic modulus of hardened cement slurry in the "N-14" layer increased to $500 \mathrm{MPa}$.

4.2. Foundation Pit Engineering. To ensure the accuracy of the simulation, the design dead load is applied to the foundation pit according to the actual situation. The steel support is installed on the retaining wall of the foundation pit, and the axial force is applied to the steel support according to the actual axial force monitoring data. The No. 1 foundation pit is located in the 98th ring to 118th ring of the shield tunnel, with a depth of $7 \mathrm{~m}$, a length of $30 \mathrm{~m}$, and a width of $14 \mathrm{~m}$. The No. 2 foundation pit is located in the 172 th ring to 190th ring of the shield tunnel, with a depth of $7.2 \mathrm{~m}$, a length of $27 \mathrm{~m}$, and a width of $16 \mathrm{~m}$, and measuring points are arranged at the bottom and bottom side of the foundation pit, of which 4 measuring points are arranged equidistantly on two long sides and 3 measuring points are arranged equidistantly on two short sides. To avoid the mutual interference between the two foundation pits and ensure the comparability of the calculated data, the independent analysis method is used in the numerical analysis model. Firstly, the model of No. 1 foundation pit is established for analysis, and then the No. 2 foundation pit is established for analysis. The model diagram is shown in Figure 2.

\section{Results and Discussion}

5.1. Analysis of Actual Monitoring Results. The structure of the shield tunnel passing through two foundation pits is similar, and the vertical distance between the two foundation pits and the shield tunnel is close. The plane length-width ratio of No. 1 and No. 2 foundation pit is 2.1 and 1.7, respectively, which is relatively close. Therefore, the field monitoring data of the two foundation pits are comparable. In the analysis of settlement caused by shield tunnel construction, the surface settlement along the longitudinal direction of the tunnel can be divided into five stages: settlement before excavation, settlement before excavation, settlement of shield body, settlement of turning overexcavation, settlement of clearance at shield tail, and 


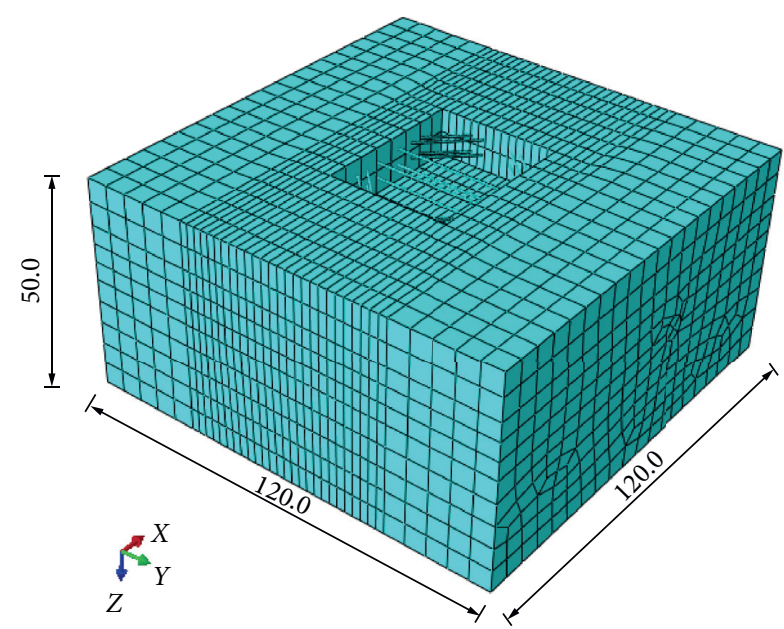

Figure 2: Model meshing.

consolidation settlement; the relationship curve between shield excavation location and foundation pit bottom settlement is shown in Figure 3.

It can be seen from the figure that the settlement law at the bottom of the foundation pit is basically consistent with that in the analysis of shield settlement, so the actual monitoring results have high reliability. Due to the corresponding changes in the settlement law of the foundation pit bottom caused by shield construction in different stages, the settlement is mainly composed of ground loss, shield turning overexcavation settlement, shield tail grouting gap settlement, etc., its size is mainly affected by the vertical distance between the measuring point and the tunnel line, the number of subway excavation rings, and the length-width ratio of the foundation pit. Due to the influence of the lag effect, the settlement of the foundation pit reaches the maximum after the shield is excavated to a distance directly below the measuring point. The ground loss caused by the shield causes a large settlement of the foundation pit. In the actual monitoring, the settlement value caused by this part is not too large. This is because synchronous grouting will be used in the excavation process, which will reduce the ground loss. After reaching the maximum settlement, affected by the high face pressure, the bottom of the foundation pit will have 1-3 mm uplift; about $50 \mathrm{~m}$ before the shield construction arrives at the foundation pit, the foundation pit bottom has the first settlement due to the disturbance of the tunnel face pressure on the foundation pit structure; in the advanced settlement stage, the maximum settlement of foundation pit No. 1 is near the end of the metro tunnel (measuring point MF-A1-MF-A5), and the maximum settlement is $6.9 \mathrm{~mm}$. In the turning overexcavation settlement stage, the foundation pit settlement is mainly affected by the amount of overbreak and turning radius. After the excavation is carried out below the foundation pit, the settlement of the foundation pit shows a decreasing trend after the shield construction passes through the foundation pit, and the settlement is gradually stable after the shield construction leaves the foundation pit for about $30 \mathrm{~m}$. Compared with No. 1 foundation pit and No. 2 foundation pit, No. 1 foundation pit has a larger length-width ratio, weaker resistance to deformation, and more vulnerability to shield excavation disturbance. Therefore, the settlement of measuring points near the metro end or far metro section is greater than that of the No. 2 foundation pit. Therefore, in the construction under similar working conditions, densified measuring points or effective engineering treatment measures should be taken to reduce the settlement of foundation pit with a large aspect ratio.

\subsection{Deformation Analysis of Foundation Pit Bottom.} Figure 4 shows the three-dimensional images of the bottom of the No. 1 and No. 2 foundation pits. The data was collected after the foundation settlement was stable and the shield tunnel excavation was completed. It can be seen from the figure that during the construction of the turning shield tunnel, the deformation of the bottom of the foundation pit along the line is irregular concave, which is mainly caused by multiple factors such as overexcavation during shield turning construction and settlement in advance during shield construction. The settlement of the middle part is larger than that of the surrounding of the foundation pit bottom. The sunken trend of the foundation pit gradually develops with the advance of the number of shield construction rings; because the settlement law of the surrounding foundation pits during shield construction is obviously affected by the lag effect of shield construction, the deformation of the bottom of the foundation pit is the largest when the shield construction position is $50 \mathrm{~m}$ below the building. The distance is greatly affected by the turning radius, the amount of turning over excavation, the type of foundation pit, and the disturbance of the foundation pits. The final deformation of the foundation pit bottom is inclined and concave towards the direction of shield construction. The maximum settlement of the foundation pit is controlled within $8 \mathrm{~mm}$. Compared with the settlement of the two foundation pits, the concave deformation caused by the disturbance of shield tunnel construction is larger because of the larger plane length-width ratio of foundation pit No. 1. The settlement near the tunnel side is greater than that at the far tunnel side. The average settlement of No. 1 foundation pit near the tunnel side is $-6.69 \mathrm{~mm}$; the average settlement of the far tunnel side is $-4.97 \mathrm{~mm}$, while that of the No. 2 foundation pit is $-5.83 \mathrm{~mm}$ and $-3.95 \mathrm{~mm}$, which are all less than that of the No. 1 foundation pit.

\subsection{Numerical Simulation Results}

5.3.1. Verification of Numerical Simulation Results. To verify the accuracy of the model, the theoretical analytical solution, the actual monitoring data, and the numerical simulation model are compared and analyzed, and the MF-A3 measurement point is selected as the verification point. The results are shown in Figure 5. It can be seen that the numerical simulation results are basically consistent with the theoretical calculation values and the measured values, with only a small error, and the relative error is about $9 \%$, indicating that the theoretical calculation and numerical simulation results have high accuracy. Comparing the actual 

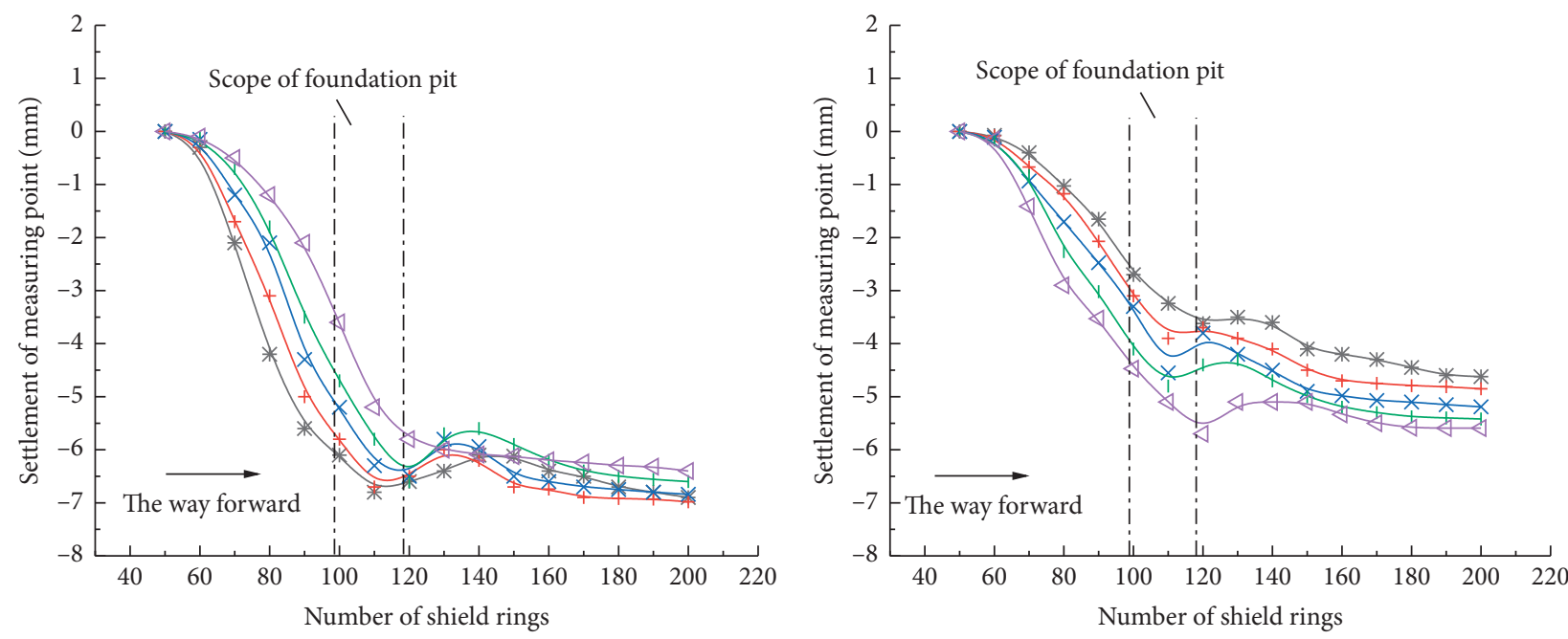

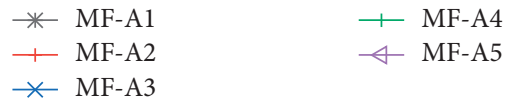

(a)

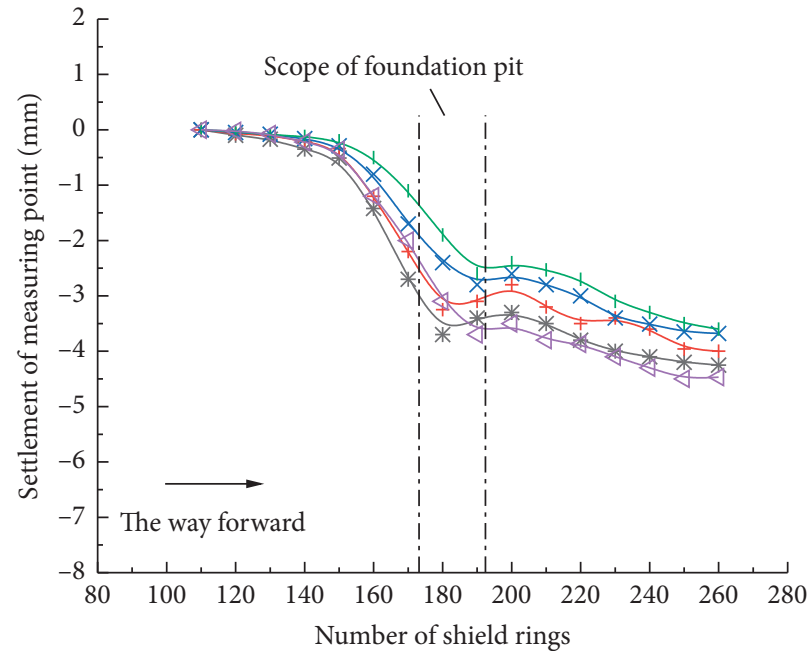

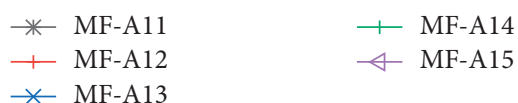

(c)

$$
\begin{array}{ll}
* \text { MF-A6 } & - \text { MF-A9 } \\
\leftarrow \text { MF-A7 } & \dashv \text { MF-A10 } \\
* \text { MF-A8 } &
\end{array}
$$

(b)

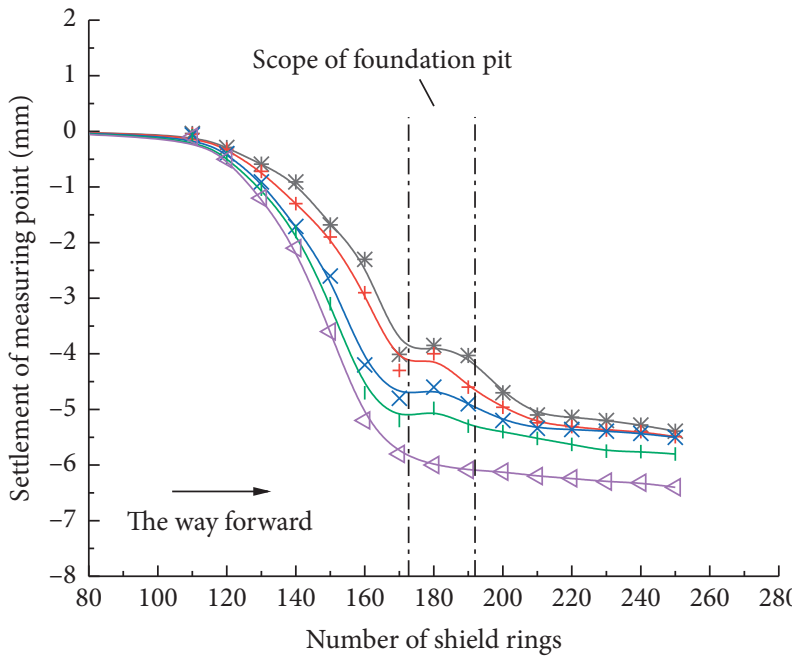

$*$ MF-A16
+ MF-A17
$*$ MF-A18
+ MF-A19

$\neg$ MF-A20

(d)

Figure 3: Longitudinal measured deformation of foundation pit. (a) No. 1 foundation pit near tunnel side. (b) No. 1 foundation pit far tunnel side. (c) No. 2 foundation pit near tunnel side. (d) No. 2 foundation pit far tunnel side.

monitoring data with the numerical simulation data, it is found that the main source of the error is that the measured value slightly lags behind the numerical simulation value. The reason is that some compensation grouting measures will be taken in the actual shield tunnel construction and the lag effect in the shield construction.

\subsubsection{Influence of Length-Width Ratio of Foundation Pit on} Settlement Mode. In the actual monitoring results, it is preliminarily considered that the plane aspect ratio of the foundation pit will have an impact on the settlement mode of the bottom of the foundation pit, and the foundation pit with a larger plane aspect ratio is more vulnerable to the disturbance of shield excavation, resulting in greater settlement. To further explore the influence of length-width ratio on the settlement mode of foundation pit structure, the foundation pit models with plane length-width ratio of 2.1, 2.0, 1.9, 1.8, and 1.7 are established for comparative analysis. To ensure the comparability of data, the center position of the foundation pit with different length-width ratio and the distance between the foundation pit and tunnel axis are the same. Run the model and extract the settlement curve of measured excavation rings and measured points, as shown in Figure 6. 


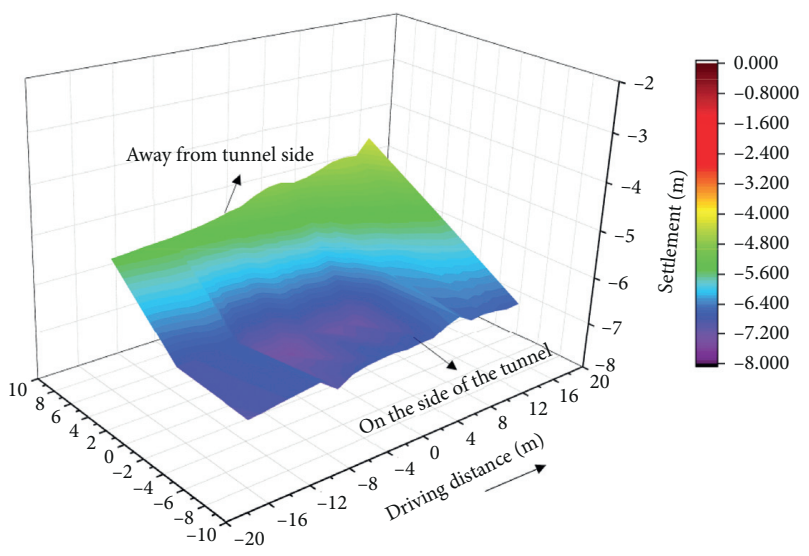

(a)

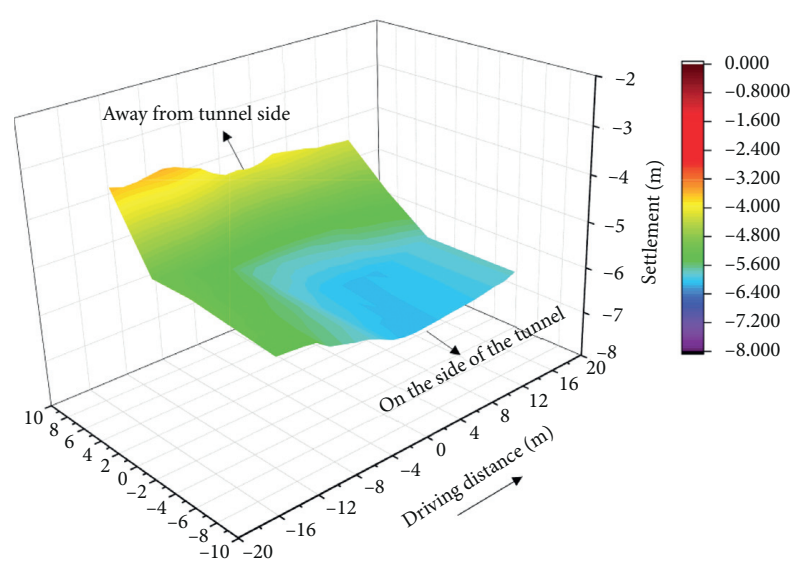

(b)

Figure 4: Three-dimensional deformation of foundation pit bottom. (a) Foundation pit No. 1. (b) Foundation pit No. 2.

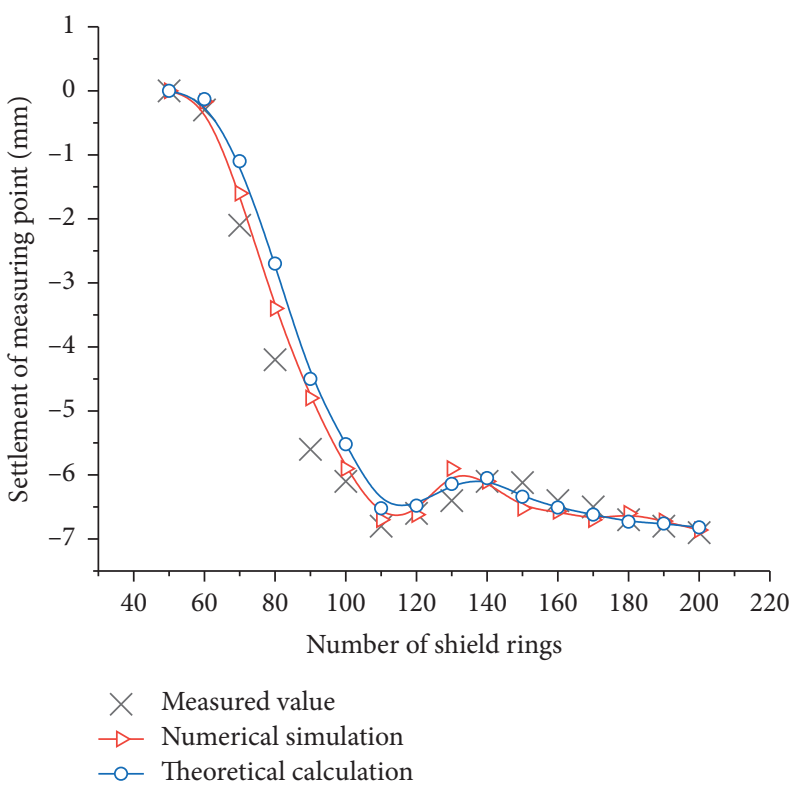

(a)

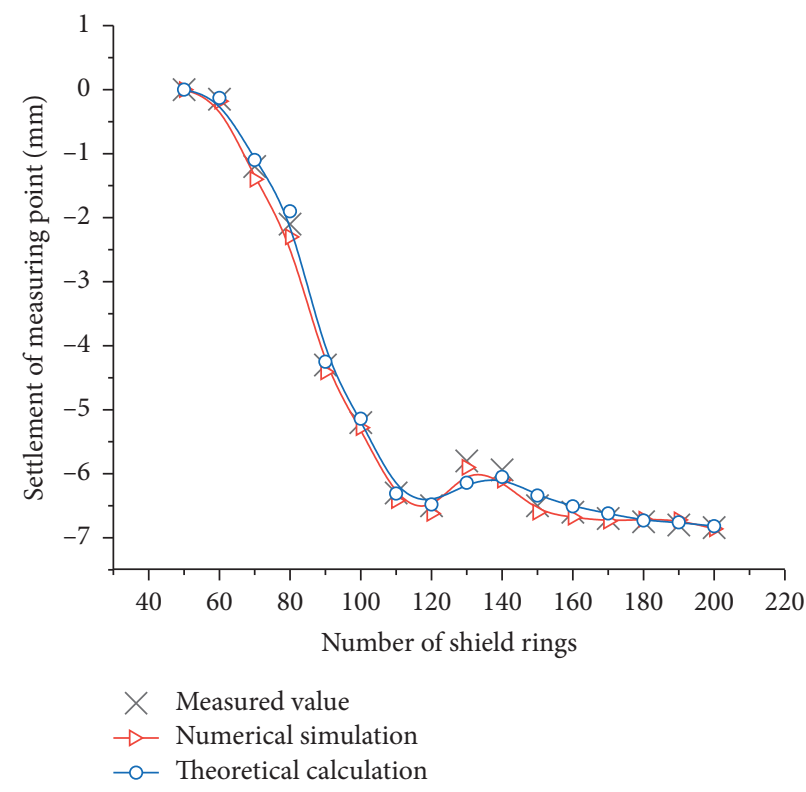

(b)

FIgURE 5: Model validation. (a) MF-A1. (b) MF-A3.

It can be seen from Figure 6 that, under the influence of the construction disturbance of the shield tunnel for the existing foundation pit, the plane aspect ratio of the foundation pit has a certain influence on its settlement mode. The larger aspect ratio makes the settlement of the foundation pit larger in the process of shield tunnel construction. For the settlement data of two different length-width ratios (2.1 and 1.7), it is found that compared with the length-width ratio of 1.7 For the foundation pit, the average settlement ratio of the foundation pit with length-width ratio of 2.1 is $37.4 \%$ higher than that in the excavation process, and the final settlement is $21.3 \%$ higher than that in the excavation process. Therefore, the foundation pit with a larger plane length-width ratio has weaker resistance to deformation and is more vulnerable to shield excavation disturbance. In the construction under similar working conditions, it is necessary to increase the measuring points or take effective engineering treatment measures to reduce the settlement.

5.3.3. Analysis of Numerical Simulation Results. Based on the actual working conditions, the numerical simulation technology is used to establish the model to calculate the ground loss caused by the construction of small turning shield tunnel and the longitudinal deformation along the shield tunnel. The calculation results are compared with the actual monitoring results and theoretical calculation results. To improve the simulation efficiency, the symmetrical analysis method is used to simulate the shield tunnel. To ensure the simulation accuracy, the shell element is used to simulate the shield shell, and the solid element is used to 


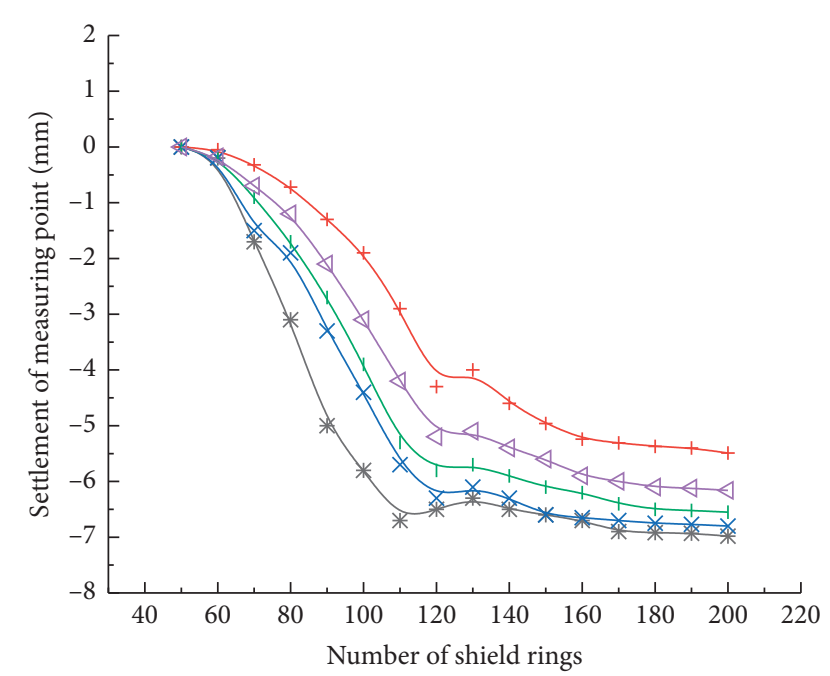

$*$ The aspect ratio is $2.1-4$ The aspect ratio is 1.8
$\times$ The aspect ratio is $2.0+$ The aspect ratio is 1.7
+ The aspect ratio is 1.9

Figure 6: Effect of aspect ratio.

simulate the shield segment; the element killing method is used in the shield excavation process, and the load is applied to the construction face during the shield construction process to simulate the tunnel face pressure, shield jacking force, and shield tail grouting process. The simulation results are shown in Figure 7.

The longitudinal deformation curve at the bottom of the foundation pit is shown in Figure 7, where $l$ is the distance between the shield construction face and the edge of the foundation pit. It can be seen from the figure that with the gradual advance of shield construction, the settlement mode of the foundation pit is constantly changing.

In the No. 1 foundation pit, when $l=15 \mathrm{~m}$, the working face is located directly below the foundation pit. Before that, the face has not reached the center of the foundation pit. Due to the disturbance of shield excavation, the bottom of the foundation pit inclines to the excavation side and produces deflection deformation. Due to the overbreak of turning shield construction and other reasons, the ground loss causes uneven soil settlement; the plane aspect ratio of the two foundation pits is large, which is easy to be disturbed by shield tunnel construction and produce deflection deformation. When the excavation is beyond the bottom of the foundation pit, the bottom of the foundation pit will be bent longitudinally, showing a concave settlement, and it will gradually become stable after the construction face leaves the scope of the foundation pit. This is basically consistent with the law analyzed in the previous part. Franzius [7] pointed out that during the construction of the turning shield, the stratum loss rate caused by the tunnel face in front of the building structure is inconsistent with that under the building structure, which is also the reason for the change of the settlement mode at the bottom of the foundation pit. The influence of disturbance on the side near the bottom of the foundation pit is more obvious, and the deformation in the longitudinal direction is greater. After the shield construction passes through the bottom of the foundation pit, the concave deflection is larger. The side farther away from the shield construction is less than the side near the tunnel in terms of settlement and deflection deformation. Compared with the deformation law of No. 1 and No. 2 foundation pits, the deformation modes of the two are the same, but because the length-width ratio of No. 1 foundation pit is greater than that of No. 2 foundation pit, the deflection deformation degree of No. 2 foundation pit is less than that of No. 1 foundation pit.

As shown in Figure 8, the lateral deformation curve of the foundation pit bottom is shown. Due to the small width of the foundation pit, compared with the longitudinal deformation, the lateral deformation of the foundation pit bottom is mainly inclined deformation, with only slight upward convex deflection deformation; through the comparative analysis of the transverse and longitudinal deformation modes of the foundation pit bottom, it is found that the longitudinal deformation and transverse deformation mode of the foundation pit bottom are quite different. The longitudinal deformation is composed of settlement and deflection deformation, while the transverse deformation is mainly settlement.

5.3.4. Stress Path Analysis. To study the deformation law of the turning shield tunnel more deeply, the stress path of typical measuring points is selected for analysis, and the variation law of stress path is used to explain the settlement mode equivalently. In the plane of $5 \mathrm{~m}$ at the bottom of the foundation pit, the measuring points M1, M2, M3, and M4 are typical measuring points for analysis. M1 is located directly below the center of the bottom of the foundation pit, M2 is located at the center of the long side of the bottom of the foundation pit, M3 is located in the center of the short side at the bottom of the foundation pit, and M4 is outside the foundation pit, $20 \mathrm{~m}$ away from the foundation pit. As shown in Figure 9, the vertical-horizontal effective stress path curve of typical measuring points is shown.

According to the stress path broken line of each measuring point, the stress path state of each measuring point can be divided into five stages. Under the conditions of turning shield construction and existing foundation pit, the stress state of soil between foundation pit and shield tunnel is complex. Because the buried depth of the three measuring points is the same, the initial stress state is the same. The first stage is the stage of shield thrust. In this stage, before the measuring point, the horizontal stress in the stratum increases due to the thrust exerted by the hydraulic jack on the working face, so the horizontal stress increases obviously, while the vertical stress almost remains unchanged. In the second stage of shield tunneling, when the tunnel face enters under the foundation pit, the thrust effect of the face is more significant, and the vertical stress of soil increases rapidly. In the third stage, the shield construction has passed through the bottom of the foundation pit, and part of the stress in the soil is released. The ground loss caused by shield excavation leads to a large decrease in stress. In the fourth stage, the shield construction enters into the stage of grouting at the 


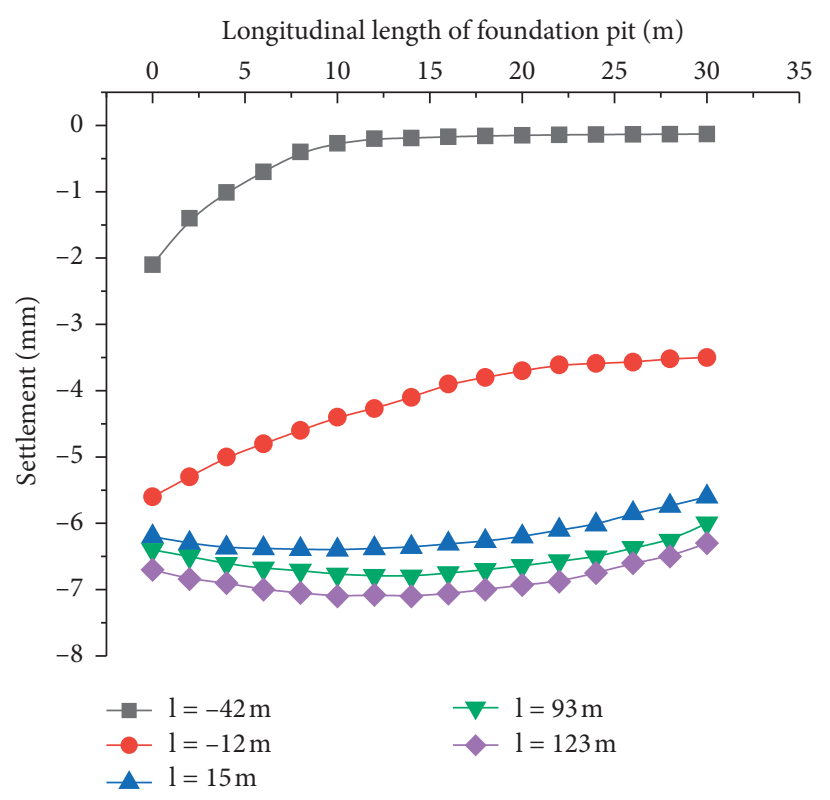

(a)

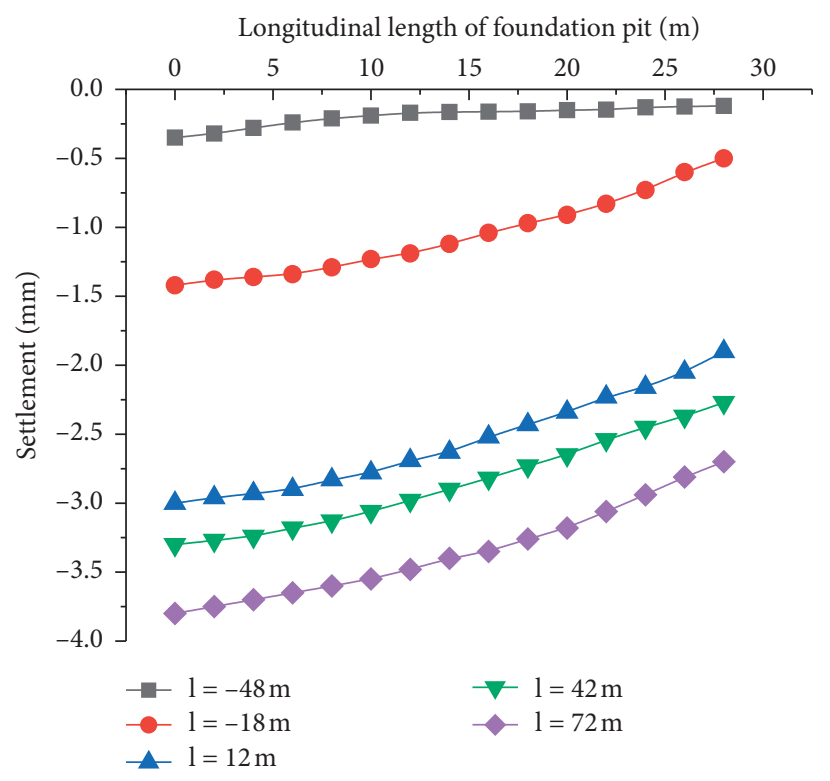

(c)

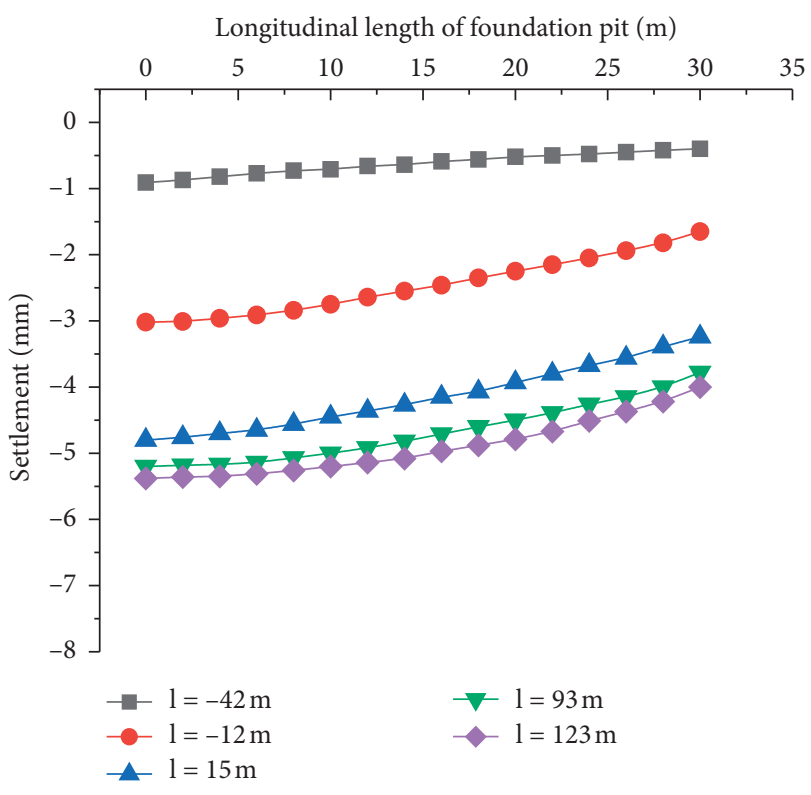

(b)

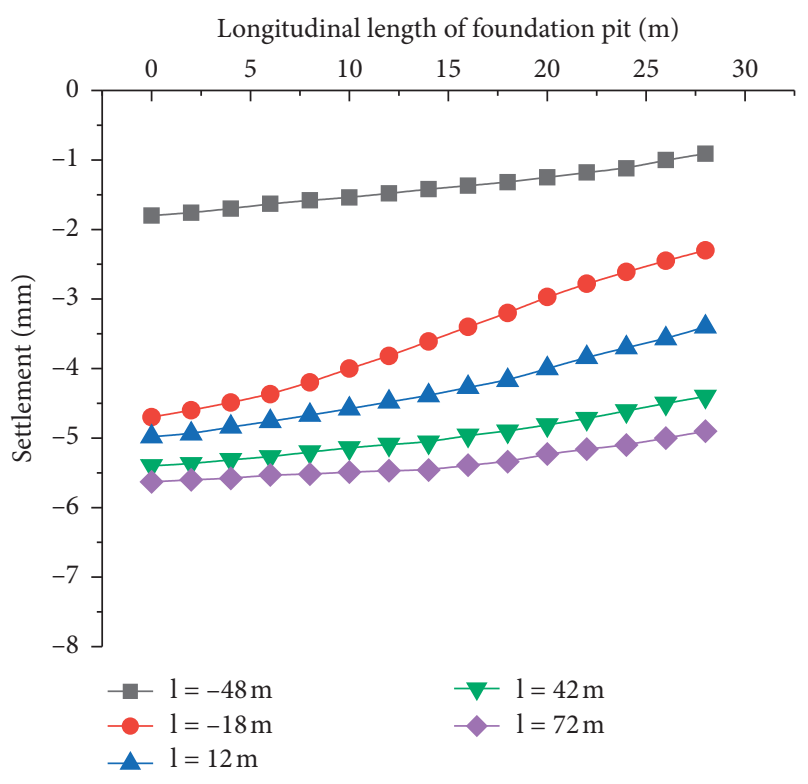

(d)

FIGURE 7: Relationship between face distance and longitudinal settlement. (a) No. 1 foundation pit near tunnel side. (b) No. 1 foundation pit far tunnel side. (c) No. 2 foundation pit near tunnel side. (d) No. 2 foundation pit far tunnel side.

tail of shield. At this time, the soil is affected by the gap settlement and grouting pressure at the tail of shield, and the vertical stress in the soil increases slightly; in the fifth stage, the shield construction is far away from the foundation pit, and the soil under the foundation pit enters the stress recovery stage, the stress and strain of the soil body tend to be stable, and the vertical stress of the measuring point slowly recovers. Due to the friction between the shield and the soil, the final horizontal stress of the soil increases, but the final vertical stress of the measuring point is less than its initial state, which is obviously the impact of soil loss. With the consolidation of soil for a long time, the vertical stress will increase slowly, and the consolidation settlement of soil and buildings will occur. The consolidation stage of soil has not been considered in this model. By comparing the stress path of soil under the conditions of straight excavation and turning excavation, it is found that the vertical stress increases slightly at first, then the stress relaxation occurs, and the horizontal stress increases due to the influence of jacking pressure of turning shield and stress release after overexcavation.

The stress paths of M1, M2, and M3 are compared and analyzed. In the first stage, because the additional stress in the center of the foundation pit is greater than that in the edge of the foundation pit, the stress increment of the measuring point M1 is obviously larger than that of the M2 


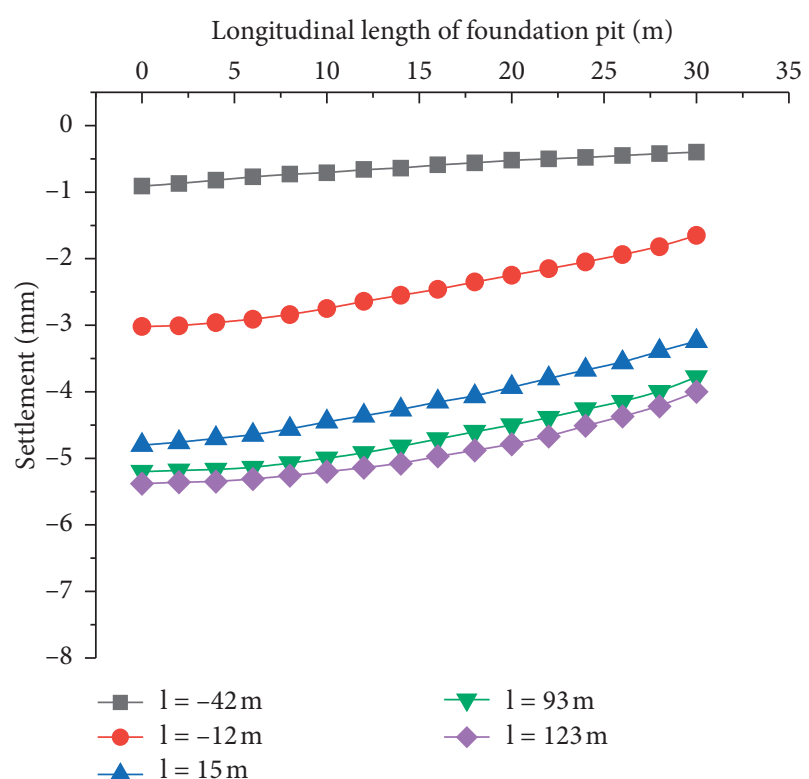

(a)

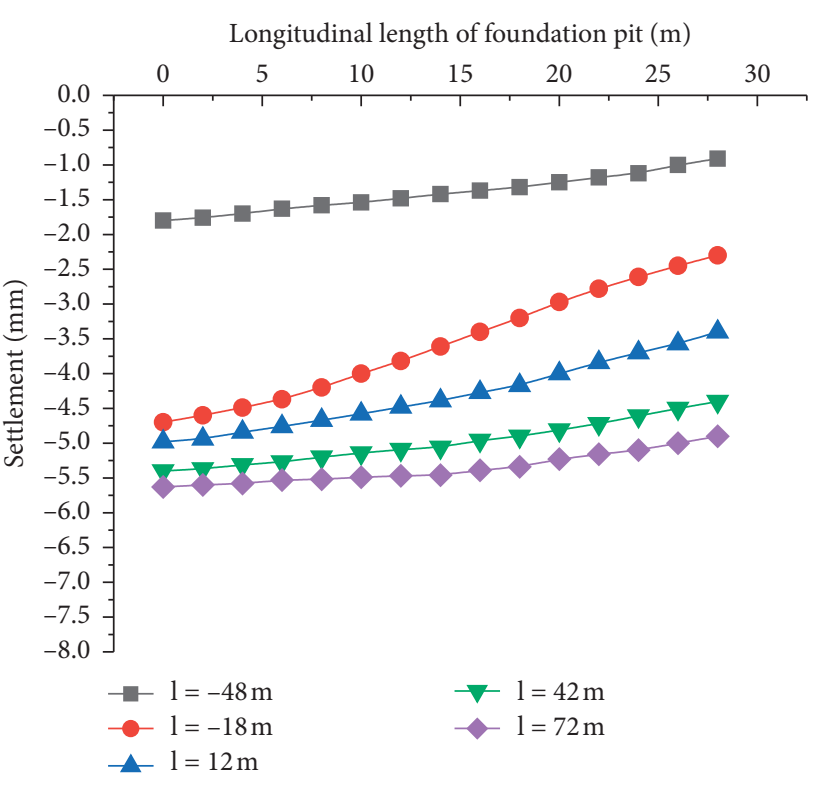

(b)

Figure 8: Relationship between face distance and lateral settlement of foundation pit. (a) No. 1 foundation pit near tunnel side. (b) No. 2 foundation pit near tunnel side.

measuring point, which is also the main reason for the longitudinal concave deformation of the foundation pit bottom. For stage 2, due to the larger additional stress of the M1 measuring point, greater vertical stress increases under the thrust of the face. The settlement of the foundation pit caused by shield excavation is mainly caused by stress release. It can be found that the stress release degree of the M1 measuring point is significantly greater than that of the M2 measuring point, which directly leads to the "concave" bending deformation of the building after shield excavation. For stage 5, although the stress increases, the deformation of the stratum increases slightly. This is because the stratum is in the stress history of "loading (stages 1-2)-unloading (stage 3)-reloading (stages 4 and 5)," and the soil deformation is controlled by rebound and recompression modulus. Finally, the horizontal stress of M1 is slightly larger than M2. In a word, the soil under the middle part of the foundation near the shield side undergoes the compression deformation caused by the increase of additional stress under the influence of the construction disturbance of the turning shield; and after the shield passes through, it also experiences the unloading deformation caused by the stress relaxation, which finally leads to the "concave" bending deformation of the foundation pit. Compared with the M2 measurement point, the M3 measurement point is farther away from the shield tunnel and is less affected by disturbance. Therefore, in the whole stress-strain path, the horizontal and vertical stresses of the M3 measurement point are less than M2. Different soil stress paths lead to different horizontal strain patterns at different positions of the bottom of the foundation pit, which eventually leads to the displacement of the bottom plane of the foundation pit tilting towards the shield tunnel.

M4 is far away from the foundation pit, which is less affected by the construction disturbance of the turning shield, so there is no additional stress increase in stage 1 . At the end of stage 2 , the vertical stress is only $78 \%$ of that of the M1 measuring point; this also leads to a lower reduction of stress at the M4 measuring point when $Z$ is reduced to the same stress level in stage 3, but the stratum settlement at M4 measuring point is larger. The reason is related to the deformation caused by stress recovery. Since the M3 measuring point does not go through an obvious loading stage (the degree of overconsolidation is low), the deformation will be obvious in stage 5 , and the stress level is still low at the end of stage 5 . By analyzing the initial state and the final state, the vertical stress of M1, M2, and M4 decreased by $20 \%, 40 \%$, and $42 \%$, respectively. Compared with the straight shield construction and the turning shield construction, the vertical stress of measuring point M4 is less affected than that of M1 and M2. The reason is that the influence of turning factors on the settlement and stress distribution mode of long-distance measuring points is greatly reduced in the process of shield excavation. 


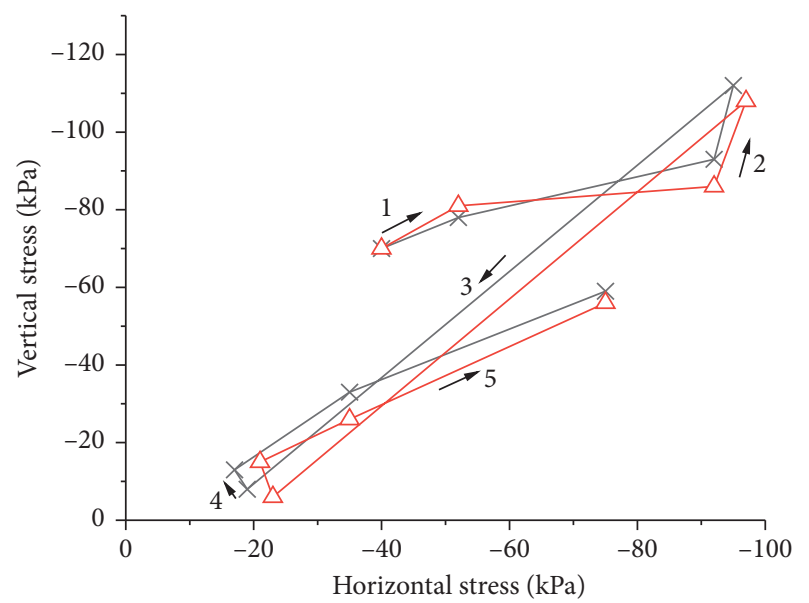

$\times$ Direct excavation

$-\triangle$ Curved excavation

(a)

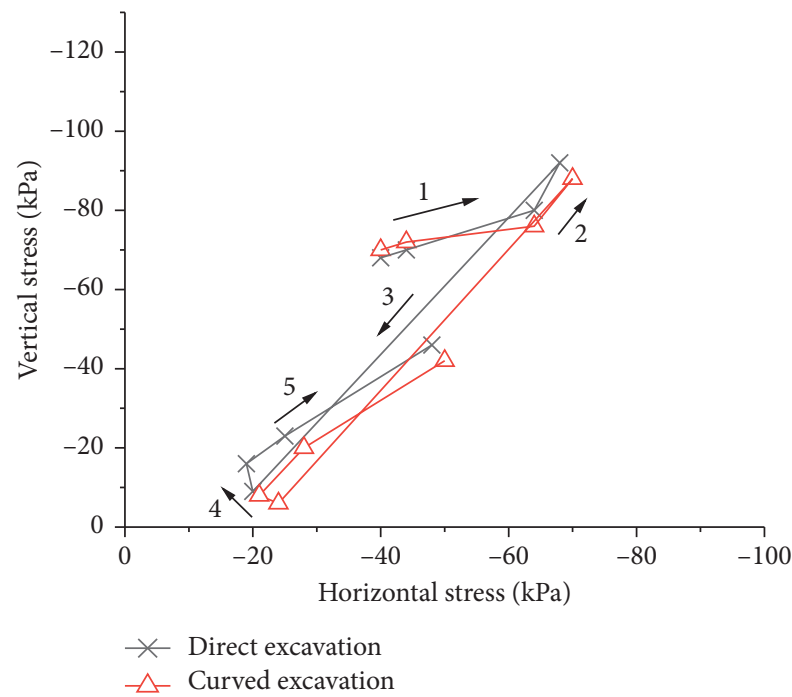

(c)

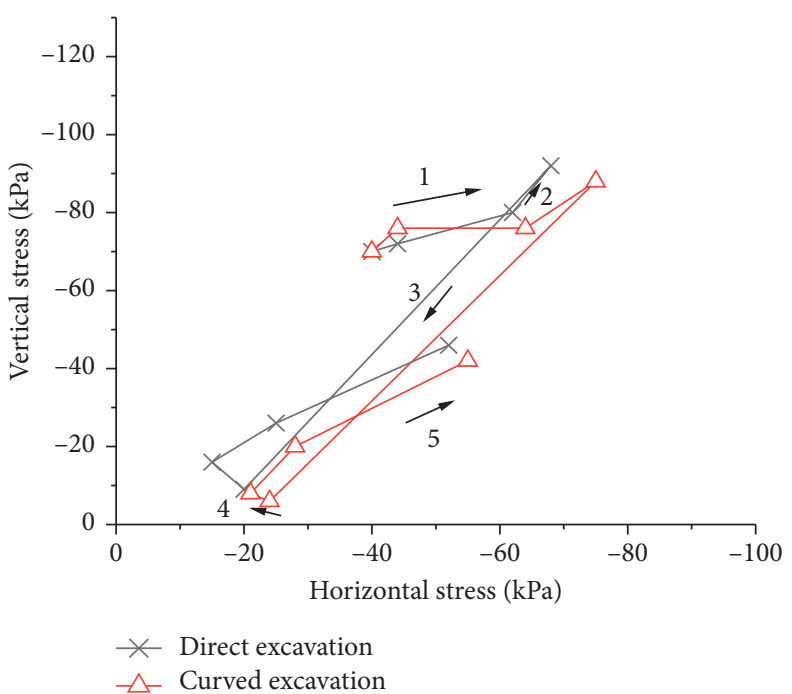

(b)

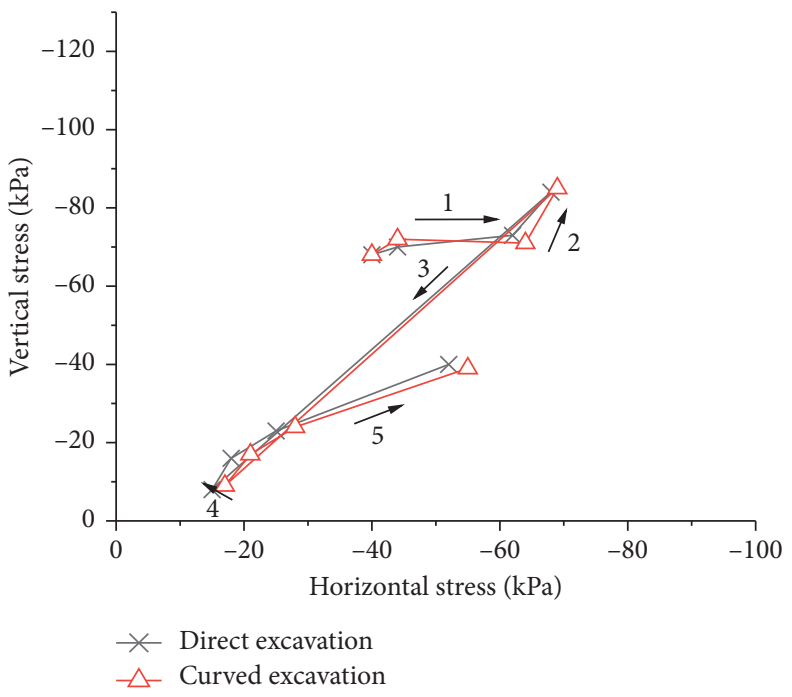

(d)

Figure 9: Change of stress path. (a) M1. (b) M2. (c) M3. (d) M4.

\section{Conclusion}

This paper investigates the disturbance analysis of turning shield construction on foundation pit under vertical cross condition. The following conclusions can be drawn:

(a) The actual monitoring results show that its size is mainly affected by the vertical distance between the measuring point and the tunnel line, the number of subway excavation rings, and the length-width ratio of the foundation pit. After the settlement reaches the peak value, it will be affected by the higher face pressure, and the bottom of the foundation pit will have a 1-3 mm uplift, and the settlement tends to be stable after the shield construction crosses the foundation pit for $30 \mathrm{~m}$. The foundation pit with a larger length-width ratio has weaker resistance to deformation under the influence of subway construction disturbance of turning shield.

(b) Through the comparative analysis of the transverse and longitudinal deformation modes of the foundation pit bottom, it is found that the longitudinal deformation and transverse deformation mode of the foundation pit bottom are quite different. The longitudinal deformation is composed of settlement and deflection deformation. When the excavation exceeds the bottom of the foundation pit, the bottom of the foundation pit presents a vertical bending and concave settlement. Compared with the longitudinal 
deformation, the lateral deformation of the foundation pit bottom is mainly inclined deformation and only slight convex deflection deformation.

(c) The change mode of stress path caused by turning shield construction can be divided into five stages, namely, the stage of shield thrust action, the stage of tunnel face entering the lower part of foundation pit, the stage of partial stress release in soil, the stage of grouting at the tail of shield, and the stage of stress recovery. By comparing the stress path of soil under the conditions of straight excavation and turning excavation, it is found that the vertical stress increases slightly at first, then the stress relaxation occurs, and the horizontal stress increases due to the influence of jacking pressure of turning shield and stress release after overexcavation.

\section{Data Availability}

The figures and tables data used to support the findings of this study are included within the article.

\section{Conflicts of Interest}

The authors declare that they have no conflicts of interest regarding the publication of this paper.

\section{Authors' Contributions}

Hong Zhang reviewed and edited the article and was responsible for conceptualization and methodology. Hua Yin established the finite element model.

\section{Acknowledgments}

The authors would like to express their sincere gratitude to all the people involved in this research project.

\section{References}

[1] J. Chen and M. Sugimoto, "Analysis on shield operational parameters to steer articulated shield," Japanese Geotechnical Society Special Publication, vol. 2, no. 42, pp. 1497-1503, 2016.

[2] G. Mollon, D. Dias, and A.-H. Soubra, "Probabilistic analyses of tunneling-induced ground movements," Acta Geotechnica, vol. 8, no. 2, pp. 181-199, 2013.

[3] A. Alsahly, J. Stascheit, and G. Meschke, "Advanced finite element modeling of excavation and advancement processes in mechanized tunneling," Advances in Engineering Software, vol. 100, pp. 198-214, 2016.

[4] P. Li, F. Wang, C. Zhang, and Z. Li, "Face stability analysis of a shallow tunnel in the saturated and multilayered soils in short-term condition," Computers and Geotechnics, vol. 107, pp. 25-35, 2019.

[5] H. Yu, C. Cai, A. Bobet, X. Zhao, and Y. Yuan, "Analytical solution for longitudinal bending stiffness of shield tunnels," Tunnelling and Underground Space Technology, vol. 83, pp. 27-34, 2019.

[6] R. Hasanpour, J. Rostami, M. Thewes, and J. Schmitt, "Parametric study of the impacts of various geological and machine parameters on thrust force requirements for operating a single shield TBM in squeezing ground," Tunnelling and Underground Space Technology, vol. 73, pp. 252260, 2018.

[7] G. Zheng, P. Lu, and Y. Diao, "Advance speed-based parametric study of greenfield deformation induced by EPBM tunneling in soft ground," Computers and Geotechnics, vol. 65, pp. 220-232, 2015.

[8] Z. Zhang, M. Zhang, Y. Jiang, Q. Bai, and Q. Zhao, “Analytical prediction for ground movements and liner internal forces induced by shallow tunnels considering non-uniform convergence pattern and ground-liner interaction mechanism," Soils and Foundations, vol. 57, no. 2, pp. 211-226, 2017.

[9] X. She and D.-J. Yuan, "Influence of shield pitch angle variation on shield-soil interaction," Rock and Soil Mechanics, vol. 41, pp. 1366-1376, 2020.

[10] X.-Y. Xie, Y.-L. Zang, B. Zhou et al., "Micro-settling control technology for shield tunnels crossing old buildings," Chinese Journal of Geotechnical Engineering, vol. 41, no. 10, pp. 1781-1789, 2019.

[11] M.-D. He, J. Liu, G.-P. Le et al., "Study of impact of shield tunneling side-crossing on adjacent high buildings," Chinese Journal of Rock Mechanics and Engineering, vol. 29, no. 3, pp. 603-608, 2010.

[12] G.-F. Lu, Q.-C. Wei, and Y.-J. Ni, "Numerical analysis on the construction disturbance of shallow excavation tunnelling considering small strain behavior of soil," China Railway Science, vol. 31, no. 1, pp. 72-78, 2010.

[13] M. Kavvadas, D. Litsas, I. Vazaios, and P. Fortsakis, "Development of a 3D finite element model for shield EPB tunnelling," Tunnelling and Underground Space Technology, vol. 65, pp. 22-34, 2017.

[14] G. Wei, S.-M. Zhang, J. Qi et al., "Study on calculation method of ground deformation induced by tunnel construction," Chinese Journal of Rock Mechanics and Engineering, no. S1, pp. 3317-3323, 2006.

[15] X.-F. Ma, J.-S. Wang, X.-Y. Li et al., "Centrifuge modeling of ground loss and settlement caused by shield tunnelling in soft ground," Chinese Journal of Geotechnical Engineering, vol. 34, no. 5, pp. 942-947, 2012.

[16] Y. Zhang, S.-N. Liu, J. Wu et al., "Sensitivity and its impact of strata parameters on ground surface settlements during shield tunnelling," Modern Tunnelling Technology, vol. 56, no. 4, pp. 127-134, 2019.

[17] M.-J. Zhang, S.-H. Li, and P.-F. Li, "Numerical analysis of ground displacement and segmental stress and influence of yaw excavation loadings for a curved shield tunnel," Computers and Geotechnics, vol. 118, Article ID 103325, 2020.

[18] G. Wei, Y. Zhou, and X. .,-J. Wei, "Research on post-construction surface settlement caused by shield tunneling," Chinese Journal of Rock Mechanics and Engineering, vol. 32, no. S1, pp. 2891-2896, 2013.

[19] H. Chakeri, B. Unver, and Y. Ozcelik, "A novel relationship for predicting the point of inflexion value in the surface settlement curve," Tunnelling and Underground Space Technology, vol. 43, pp. 266-275, 2014.

[20] J. Ninić and G. Meschke, "Simulation based evaluation of time-variant loadings acting on tunnel linings during mechanized tunnel construction," Engineering Structures, vol. 135, pp. 21-40, 2017.

[21] V. Vgerinos, D. M. Potts, and J. R. Standing, "Numerical investigation of the effects of tunnelling on existing tunnels," Géotechnique, vol. 67, no. 9, pp. 808-822, 2017.

[22] P. Li, S.-J. Du, S.-L. Shen, Y.-H. Wang, and H.-H. Zhao, "Timoshenko beam solution for the response of existing 
tunnels because of tunneling underneath," International Journal for Numerical and Analytical Methods in Geomechanics, vol. 40, no. 5, pp. 766-784, 2016.

[23] H.-N. Wu, S.-L. Shen, S.-M. Liao, and Z.-Y. Yin, "Longitudinal structural modelling of shield tunnels considering shearing dislocation between segmental rings," Tunnelling and Underground Space Technology, vol. 50, pp. 317-323, 2015.

[24] X.-T. Lin, R.-P. Chen, H.-N. Wu, and H.-Z. Cheng, "Deformation behaviors of existing tunnels caused by shield tunneling undercrossing with oblique angle," Tunnelling and Underground Space Technology, vol. 89, pp. 78-90, 2019.

[25] N. A. Do, D. Dias, and P. Oreste, "Three-dimensional numerical simulation of mechanized twin stacked tunnels in soft ground," Journal of Zhejiang University (Science A), vol. 15, no. 11, pp. 896-913, 2015.

[26] X.-L. Jiang and Z.-M. Zhao, "Application of image method in calculation of tunneling-induced soil displacement," Journal of Harbin Institute of Technology, no. 6, pp. 801-803, 2005.

[27] R. D. Mindlin, "Force at a point in the interior of a semiinfinite solid," Physics, vol. 7, no. 5, pp. 195-202, 1936.

[28] C. Sagaseta, "Analysis of undraind soil deformation due to ground loss," Géotechnique, vol. 37, no. 3, pp. 301-320, 1987.

[29] H.-S. Zheng, H.-L. Fu, and Y. Shi, "Calculation of surface settlement caused by excavation of shield tunnel with small turning radius," Chinese Journal of Geotechnical Engineering, vol. 43, pp. 165-173, 2020.

[30] N.-A. Do, D. Dias, P. Oreste, and I. Djeran-Maigre, "Threedimensional numerical simulation for mechanized tunnelling in soft ground: the influence of the joint pattern," Acta Geotechnica, vol. 9, no. 4, pp. 673-694, 2014. 